\title{
Phylogeny of chitinases and its implications for estimating horizontal gene transfer from chitinase-transgenic silver birch (Betula pendula)
}

\author{
Katileena LOHTANDER ${ }^{1 *}$, Hanna-Leena PASONEN ${ }^{2}$, Markku K. AALTO ${ }^{3}$, Tapio PALVA ${ }^{3}$, Ari PAPPINEN $^{4}$ \\ and Jouko RIKKINEN ${ }^{5}$ \\ 1 Botanical Museum, P.O. Box 7, 00014 University of Helsinki, Finland \\ 2 Department of Applied Biology, P.O. Box 27, 00014 University of Helsinki, Finland \\ 3 Department of Biosciences, P.O. Box 47, 00014 University of Helsinki, Finland \\ ${ }^{4}$ North Karelia University of Applied Sciences, Tikkarinne 9, 80200 Joensuu, Finland \\ 5 Department of Ecology and Systematics, Division of Systematics, P.O. Box 47, 00014 University of Helsinki, Finland
}

Chitinases are hydrolytic enzymes that have been employed in biotechnology in attempts to increase plants' resistance against fungal pathogens. Genetically modified plants have given rise to concerns of the spreading of transgenes into the environment through vertical or horizontal gene transfer (HGT). In this study, chitinaselike sequences from silver birch (Betula pendula) EST-libraries were identified and their phylogenetic relationships to other chitinases were studied. Phylogenetic analyses were used to estimate the frequency of historical gene transfer events of chitinase genes between plants and other organisms, and the usefulness of phylogenetic analyses as a source of information for the risk assessment of transgenic silver birch carrying a sugar beet chitinase IV gene was evaluated. Thirteen partial chitinase-like sequences, with an approximate length of $600 \mathrm{bp}$, were obtained from the EST-libraries. The sequences belonged to five chitinase classes. Some bacterial chitinases from Streptomyces and Burkholderia, as well as a chitinase from an oomycete, Phytophthora infestans, grouped together with the class IV chitinases of plants, supporting the hypothesis that some class IV chitinases in bacteria have evolved from eukaryotic chitinases via horizontal gene transfer. According to our analyses, HGT of a chitinase IV gene from eukaryotes to bacteria has presumably occurred only once. Based on this, the likelihood for the HGT of chitinase IV gene from transgenic birch to other organisms is extremely low. However, as risk is a function of both the likelihood and consequences of an event, the effects of rare HGT event(s) will finally determine the level of the risk.

Keywords: birch / chitinase / horizontal gene transfer / phylogeny / risk assessment / transgenic tree

\section{INTRODUCTION}

Chitinases are hydrolytic enzymes, many of which have an important role as part of the inducible plant defense system (Boller, 1987; Collinge et al., 1993). They are able to catalyze the hydrolysis of chitin, the primary structural component of the cell wall of all true fungi (Bartnicki-Garcia, 1968). Class I and V chitinases have been shown to inhibit the growth of various fungal species in vitro (e.g. Arlorio et al., 1992; Mauch et al., 1988; Melchers et al., 1994; Schlumbaum et al., 1986; Vierheilig et al., 2001), and various chitinase transgenes have been tested in attempts to increase plants' resistance against fungal diseases (e.g.

*Corresponding author: katileena.lohtander@helsinki.fi
Asao et al., 1997; Broglie et al., 1991; Datta et al., 2000; Emani et al., 2003; Grison et al., 1996; Lorito et al., 1998; Vellice et al., 2006). Most research has been done on crop plants, but some tests have also been carried out with trees (Bolar et al., 2000, 2001; Pappinen et al., 2002). For example, the effects of the sugar beet chitinase IV on the fungal disease resistance of silver birch (Betula pendula) have been tested in the greenhouse (Pappinen et al., 2002) and in a field trial (Pasonen et al., 2004).

Chitinases are classified in two main groups (glycosyl hydrolase families 18 and 19) that have no significant amino acid sequence identity or any similarity in threedimensional protein structures (Davies and Henrissat, 1995). Chitinases of glycosyl hydrolase family 18 are present in many organisms, including viruses, archaea, 


\section{K. Lohtander et al.}

bacteria, animals, plants, and fungi. Most of the presently known family 19 glycosyl hydrolases have been found among plants, and many plants are known to contain multiple copies of these genes (e.g. Davis et al., 1991). These chitinases are classified in three subgroups: class I, II, and IV chitinases. Chitinases belonging to class I are targeted to vacuoles, while class II and IV chitinases are secreted into intercellular spaces. Plant chitinases from class III and V belong to glycosyl hydrolase family 18 (Beintema, 1994).

The potential large-scale use of transgenic organisms has given rise to concerns related to the spreading of transgenes into the environment, either through microbial processes (horizontal gene transfer, HGT) or reproductive phenomena (vertical gene transfer) (e.g. Conner et al., 2003; Wolfenbarger and Pfifer, 2000). Usually, HGT is defined as the transfer of genetic material between organisms that are not sexually compatible with each other (Gay, 2001). However, that definition as such is not applicable to bacteria, since HGT is the analogue of sexuality in bacteria. Thus, HGT in bacteria can be defined as any process in which bacteria incorporates genetic material from another organism. Prokaryotes are known to assimilate and integrate exogenous DNA, and plasmid elements (promoters, etc.) having bacterial origin may facilitate HGT from transgenic plants to bacteria (e.g. Nielsen et al., 1998, see for review e.g. Heuer and Smalla, 2007; Monier et al., 2007; Pontiroli et al., 2007). The most likely bacterial candidates for HGT from genetically modified plants are symbiotic and pathogenic microbes living in the plant rhizosphere (e.g. Lilley et al., 1994; Troxler et al., 1997; van Elsas et al., 1989, 2003). So far, researchers have been able to demonstrate HGT from genetically modified plants to micro-organisms like plant-associated fungi (Hoffman et al., 1994) or bacteria (Nielsen et al., 2000) only under optimized laboratory conditions or in soil microcosms. Several experimental studies have failed in demonstrating HGT from transgenic plants to bacteria (Bertolla and Simonet, 1999; Gebhard and Smalla, 1999; Nielsen et al., 1997, 1998), and to our knowledge, HGT from transgenic plants to other organisms has not been detected in field conditions. In the light of present knowledge, HGT can occur, but at such low frequencies that detecting it is extremely difficult, mainly due to the huge sampling efforts needed and the nonculturable nature of most bacteria (Heinemann and Traavik, 2004; Nielsen and Townsend, 2004).

Phylogenetic analyses provide a tool for seeking information on the historical HGT events that have occurred during the course of evolution. A standard phylogenetic analysis provides information on the evolutionary history of single genes, and numerous phylogenetic studies have provided circumstantial evidence for HGT events during the course of evolution, although some reports of HGT have been considered controversial (see e.g. Brinkman et al., 2002). Whole genome sequence comparisons, as well as other studies, have revealed that HGTs among bacteria are probably more numerous than previously thought (Ke et al., 2000; Koonin et al., 2001; Koski et al., 2000; Ochman et al., 2000; van Elsas et al., 2003; Wiener et al., 1998), and evidence for HGT between the archaeal, bacterial and/or eukaryote domains is steadily accumulating (e.g. Baker, 1998; Brinkman et al., 2001; Buades and Moya, 1996; Furner et al., 1986; Holmgren and Bränden et al., 1989; Intrieri and Buiatti, 2001; Katz, 1996; Klotz et al., 1997; Royo et al., 2000). Phylogenetic analyses have revealed HGT events even between divergent groups like plants or animals and bacteria. For example, Gamieldien et al. (2002) used phylogenetic methods to show that the mammalian pathogen Mycobacterium tuberculosis has acquired several protein-coding genes from eukaryotes through horizontal gene transfer.

In this paper, we identified all chitinase-like sequences found in silver birch EST-libraries, and studied their phylogenetic relationships to other published chitinase sequences, with a special emphasis on the sugar beet chitinase IV that was previously transferred to silver birch in order to increase birch's resistance against fungal diseases. We used phylogenetic analyses to estimate the frequency of the probable HGT events of chitinase genes from plants to other organisms and discuss the applicability of the information obtained from the phylogenetic analyses to the risk assessment of genetically modified plants.

\section{RESULTS}

\section{Amino acid sequences of glycosyl hydrolase family 19 chitinases}

Thirteen partial chitinase-like sequences, with an approximate length of $600 \mathrm{bp}$, were identified from the silver birch (Betula pendula) EST-libraries. These sequences belonged to five chitinase classes: class I and II (580-749 bp), and IV (633 and $641 \mathrm{bp}$ ) chitinases of the family 19 glycosyl hydrolases, and class III (604 bp) and class V chitinases (666 and $673 \mathrm{bp}$ ) of the family 18 glycosyl hydrolases. The alignment of amino acid sequences of class I, II and IV chitinases resulted in a data set of 271 characters, of which 221 characters were parsimonyinformative. Sequences of class IV chitinases differed from the others by having two long deletions. These and five other long indels in the alignment were treated as single character states (presence/absence). The phylogenetic analysis resulted in one most parsimonious tree (Fig. 1), with a length of 2131 steps and a consistency index (CI) 


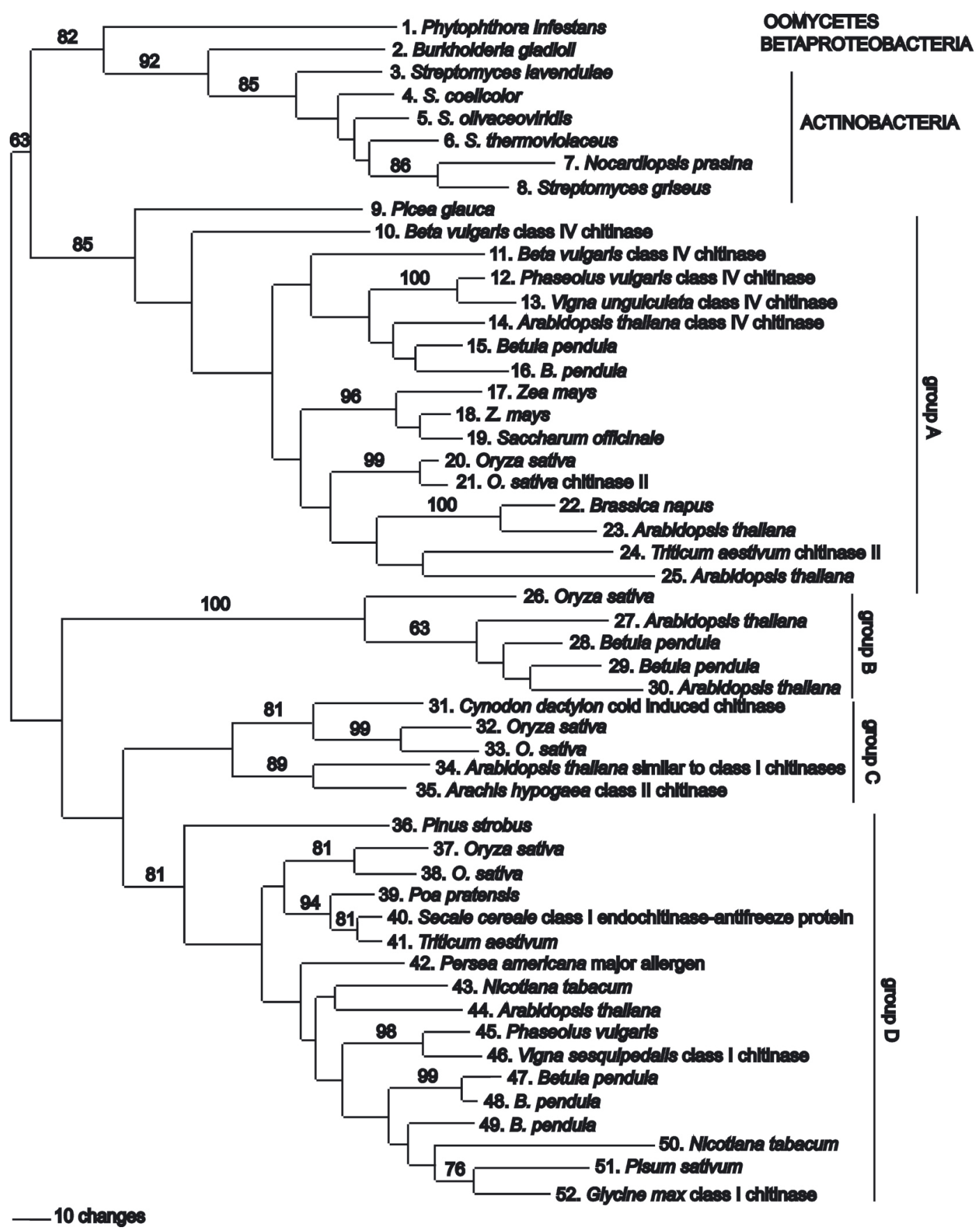

PLANTS

Figure 1. The most parsimonious tree based on $\mathbf{5 5}$ family $\mathbf{1 9}$ glycosyl hydrolase amino acid sequences. Bootstrap support $(>50 \%)$ are shown at nodes. GenBank entries for the sequences are: 1: AAN31509, 2: BAA92252, 3: AAD32750, 4: CAD55444, 5: CAB37321, 6: BAA88834, 7: BAC45252, 8: BAA23739, 9: T09131, 10: AAA32916, 11: CAA53544, 12: CAA40474, 13: S57476, 14: CAA74930, 15: AJ606365, 16: AJ606366, 17: AAA33445, 18: AAA33444, 19: AAK92198, 20: CAD41543, 21: T03405, 22: CAA43708, 23: AAB64048, 24: AAD28730, 25: AAB64049, 26: BAC55635, 27: AAL90922, 28: AJ606367, 29: AJ606368, 30: NP_172076, 31: AAC95376, 32: BAA95846, 33: AAB67171, 34: AAC72865, 35: CAA57773, 36: AAC49718, 37: BAA03749, 38: BAA03751, 39: AAF04454, 40: AAG53609, 41: BAB82473, 42: CAB01591, 43: AAA34070, 44: AAG51023, 45: AJ606369, 46: AJ606370, 47: AAA33756, 48: AAG23965, 49: S20737, 50: CAA45359, 51: AAF17593, 52: AJ606371, 53: AJ606372, 54: AJ606373, 55: AJ606374. 


\section{K. Lohtander et al.}

of 0.52 (excluding uninformative characters). The chitinases were divided into two major groups (Fig. 1). The first group consisted of sequences from bacteria, plants, and an oomycete (Phytophthora infestans), and had $81 \%$ bootstrap support. The oomycete chitinase grouped together with bacterial chitinases with 53\% bootstrap support. These sequences formed a sister group to all plant chitinases in group A, which had a bootstrap support of $82 \%$. A chitinase of Picea glauca appeared as a sister to all other plant chitinases in that group. Two silver birch chitinase-like sequences grouped together with class IV chitinases from Beta, Phaseolus, Vigna and Arabidopsis, but this subgroup did not have any bootstrap support. Another subgroup included several monocotyledon sequences (Oryza, Saccharum, Triticum, Zea) and some Arabidopsis and Brassica sequences (Fig. 1).

The second main group in the phylogenetic tree included only plant chitinases (Fig. 1). Two silver birch chitinase-like sequences grouped together with similar sequences from Oryza sativa and Arabidopsis thaliana with 100\% bootstrap support (group B; Fig. 1). Among the remaining sequences, a clade (with $89 \%$ support) consisting of monocotyledon chitinases (Cynodon and Oryza; bootstrap support of $94 \%$ ) formed a sister group to sequences from Arabidopsis thaliana and Arachis hypogaea (group C; Fig. 1). The large group D in Figure 1 (with no support) consisted of a Pinus strobus chitinase as a sister group to the other sequences. The ingroup comprised of monocotyledon chitinases (Oryza, Poa, Secale, Triticum; $61 \%$ support) formed a sister group to a clade consisting of six silver birch chitinases (in two groups) and sequences from Persea americana, Nicotiana, Arabidopsis, and several fabalean species (Glycine, Phaseolus, Pisum, Vigna). Only certain small groups within the group D were supported.

\section{DNA sequences of class IV chitinases}

The alignment of 28 class IV chitinase DNA sequences resulted in a data set with a length of 719 characters, of which 574 (70 characters from indels) were parsimonyinformative. The phylogenetic analysis yielded four equally parsimonious trees, from which a strict consensus tree was calculated (Fig. 2). The tree was far better supported than the corresponding group in the amino acid tree (Fig. 1), having class IV chitinases of monocotyledons (Oryza, Saccharum, Triticum, Zea) and dicotyledons (Arabidopsis, Beta, Betula, Phaseolus, Vigna) in separate groups (with bootstrap support $85 \%$ and $70 \%$, respectively).

The DNA tree (Fig. 2) had a slightly different topology and a better overall bootstrap support than the tree based on amino acid sequences (Fig. 1). This held true even when only class IV chitinase sequences were used in the analysis of amino acid sequences (tree not shown). In the DNA tree (Fig. 2), both Beta vulgaris sequences grouped together, and the monocots and dicots formed supported groups of their own. On the other hand, when DNA sequences of all the family 19 glycosyl hydrolases present in the amino acid tree were analyzed, many branches collapsed and the overall bootstrap support was drastically reduced (tree not shown). This could possibly be attributed to saturation of third codon positions.

Among the chitinase-like sequences from Betula, chitinases 15 and 16 grouped with class IV chitinases of the family 19 glycosyl hydrolases (Fig. 1). Betula chitinase-like sequences 45-46, as well as 52-55, grouped together with class I chitinases, and sequences 28 and 29 were nested within a clade of previously known chitinases from Oryza and Arabidopsis. The amino acid sequences of the latter group (B in Fig. 1) clearly differed from other family 19 glycosyl hydrolases. As the group was distinct, well-supported (100\% bootstrap support) and contained both monocotyledon (Oryza) and dicotyledon (Arabidopsis and Betula) sequences, it may actually represent a chitinase class of its own. Group C (Fig. 1), which also included both monocotyledon (Cynodon, Oryza) and dicotyledon (Arabidopsis, Arachis) sequences, might also represent a distinct class of chitinases.

\section{Amino acid sequences of glycosyl hydrolase family 18 chitinases}

The alignment of the amino acid sequences of class III chitinases (Fig. 3) resulted in a data set of 408 characters, of which 327 were parsimony-informative. The phylogenetic analysis resulted in one most parsimonious tree (3520 steps long) with a CI of 0.6 (Fig. 3). The tree consisted of a bacterial chitinases (55\% bootstrap support) as a sister group to chitinases from fungi and plants. The latter clade had 100\% bootstrap support. The fungal chitinases, all originating from either zygomycetes or ascomycetes, formed a monophyletic sister group to the plant chitinases, including two chitinase-like sequences from silver birch (Fig. 3). Within the plant clade, sequences from monocotyledons (Oryza, Triticum, Zea) and dicotyledons (the other plants in Fig. 3) were intermixed. Chitinases from various species of the Fabaceae (Cicer, Glycine, Vigna) and Solanaceae (Capsicum, Nicotiana) were found in two separate groups, suggesting past gene duplication events. The silver birch chitinase-like sequences grouped together with chitinases from Nicotiana tabacum, but this grouping did not have any bootstrap support.

Alignment of the amino acid sequences of class $\mathrm{V}$ chitinases (Fig. 4) resulted in a data set of 605 characters, of which 448 were parsimony-informative. 


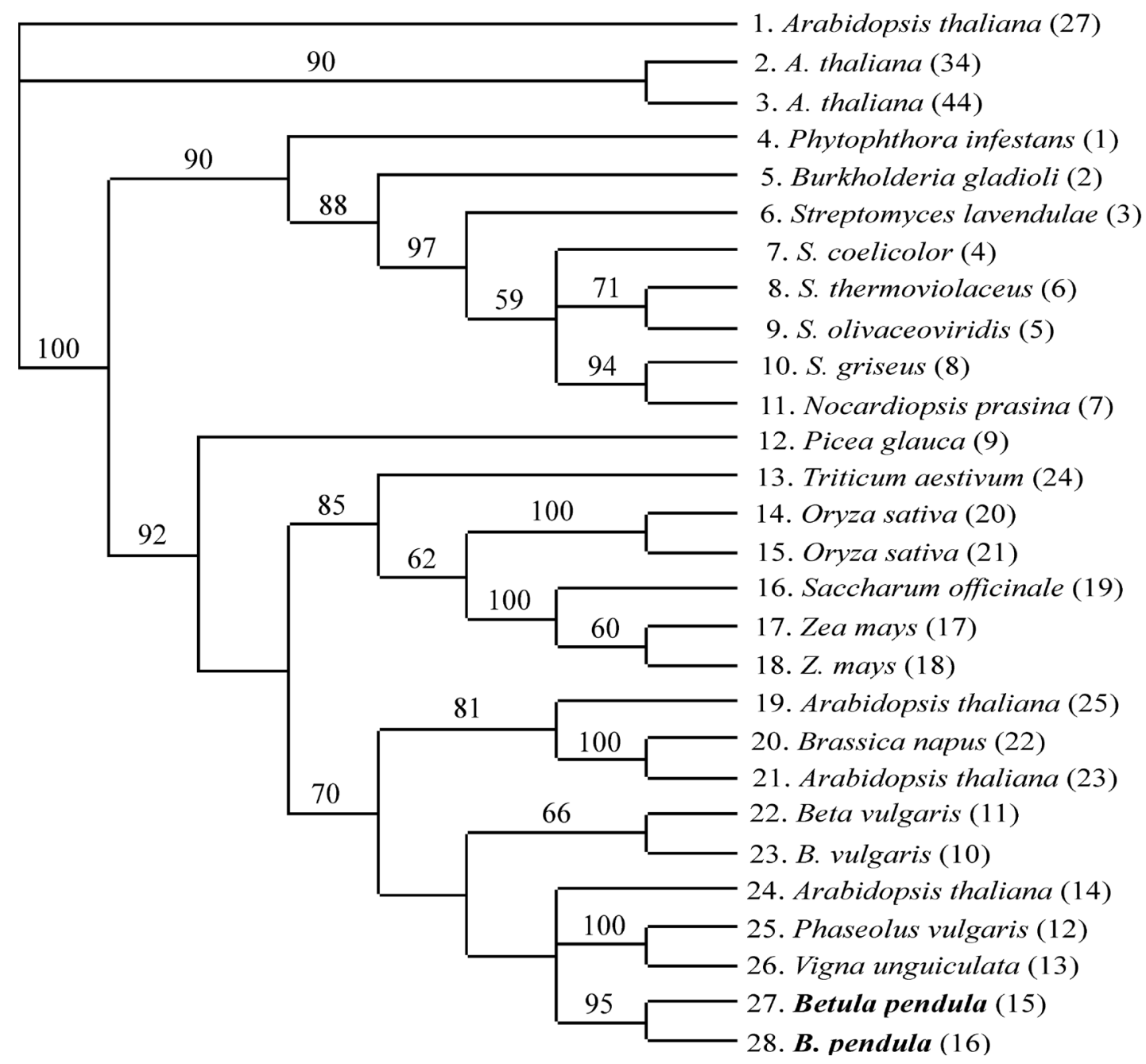

Figure 2. A consensus of four equally parsimonious trees based on the family 19 glycosyl hydrolase DNA sequences. Bootstrap support values $(>50 \%)$ are shown at nodes. The numbers in parentheses refer to the sequence number in the corresponding amino acid group (class IV chitinases) in the Figure 1.

The phylogenetic analysis yielded one most parsimonious tree (7963 steps long, CI of 0.45) with generally poor bootstrap support (Fig. 4). The tree included chitinases from a very wide variety of Archaea, Bacteria, Eukaryotes and viruses. Only a few groups within the tree were well-supported. One of the supported (97\%) clades included all the plant class $\mathrm{V}$ chitinases (sequences 16-21 in Fig. 4), including two silver birch chitinase-like sequences.

\section{DISCUSSION}

\section{Phylogeny of chitinases}

A total of thirteen chitinase-like sequences belonging to five classes (I-V) were found from the silver birch
EST-libraries. Although these sequences were somewhat shorter (523-673 bp for DNA/ca. 200 aa for protein sequences) than most of the previously published sequences in GenBank, they were informative enough to be useful in phylogenetic analyses. In each phylogenetic tree (see Figs. 1-4) the birch chitinase-like sequences were nested within the other plant chitinases, as expected.

The general topology of the class I chitinases of group D (Fig. 1) was mostly congruent with the phylogeny of vascular plants: the pine (Pinus strobus) sequence appeared as a sister group to a clade consisting of monocotyledon and dicotyledon chitinases that formed monophyletic groups. The fabalean chitinases (Glycine, Phaseolus, Pisum and Vigna) formed two groups within the dicotyledon clade in the group $\mathrm{D}$, which possibly indicates historical gene duplication within the lineage. 


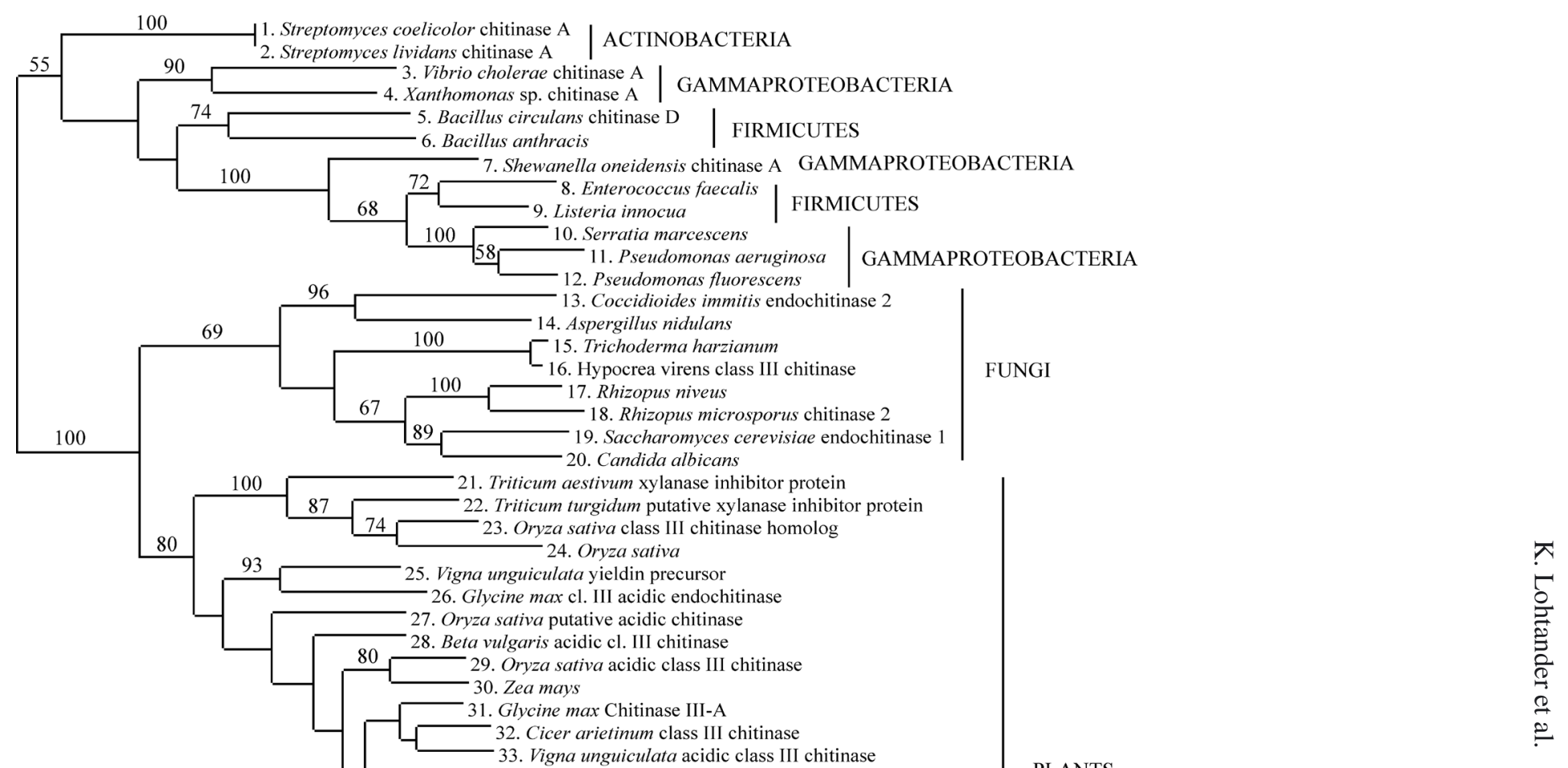

Figure 3. The most parsimonious tree based on $\mathbf{4 5}$ class III-like chitinases of the family $\mathbf{1 8}$ glycosyl hydrolase amino acid sequences. Bootstrap support (> 50\%) are shown at nodes. The GenBank entries for the sequences are: 1: BAA75642, 2: BAA02918, 3: AAC72236, 4: BAA36460, 5: BAA34114, 6: NP_657687, 7: AAN57059, 8: AAO80244, 9: CAC97226, 10: BAA76623, 11: NP_250990, 12: ZP_0086322, 13: P54197, 14: BAA36223, 15: CAA56315, 16: AAL78811, 17: BAA01018, 18: BAA01022, 19: NP_013388, 20: AAC49409, 21: CAD19479, 22: CAC87260, 23: BAA77773, 24: BAA23807, 25: BAA92940, 26: BAA25015, 27: BAB84602, 28: AAB28479, 29: BAC06302, 30: AAB47176, 31: BAA77675, 32: CAA49998, 33: CAA61280, 34: CAA77657, 35: CAA77656, 36: AJ606375, 37: CAB66334, 38: BAA23809, 39: BAC55717, 40: BAB90565, 41: CAA61279, 42: AAN37391, 43: BAC11893, 44: BAA21873, 45: BAC11892. 


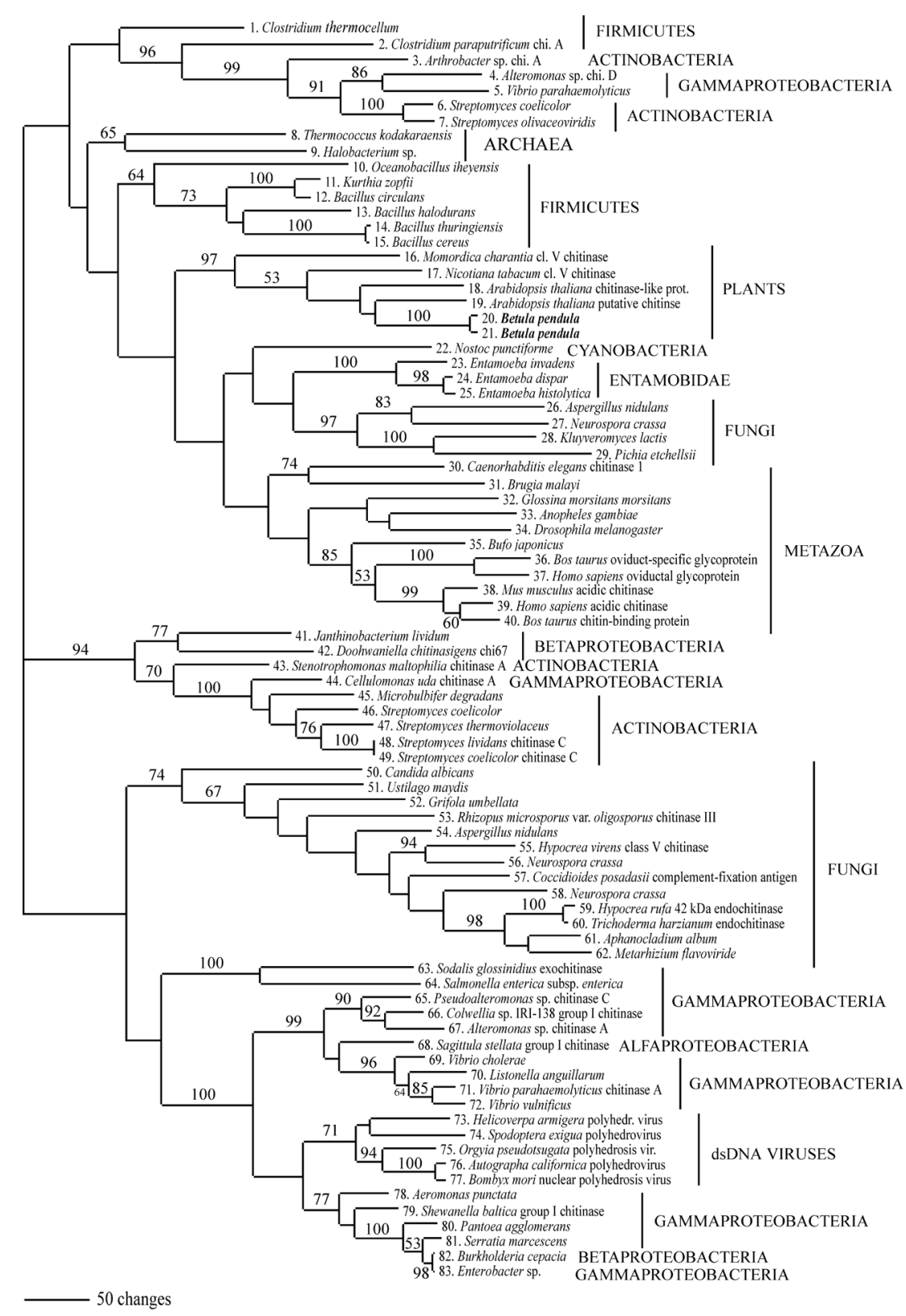

Figure 4. The most parsimonious tree based on the class V-type chitinases of the family 18 glycosyl hydrolase amino acid sequences. Bootstrap support $(>50 \%)$ are shown at nodes. GenBank entries for the sequences are: 1: ZP_00060343, 2: BAA34922, 3: CAB62382, 4: BAB79618, 5: NP_800342, 6: CAB76866, 7: CAB83055, 8: BAA88380, 9: AAG19274, 10: BAC12747, 11: BAA09831, 12: AAF74782, 13: BAB04635, 14: AAL17867, 15: BAB16891, 16: AAM18075, 17: CAA54373, 18: CAB78982, 19: CAA19699, 20: AJ606375, 21: AJ606377, 22: ZP_00108998, 23: AAB52724, 24: AAB52722, 25: AAB52723, 26: AAG34171, 27: EAA32938, 28: CAA25334, 29: CAC34265, 30: AAA83586, 31: AAA27854, 32: AAL65401, 33: AAB87764, 34: AAF46663, 35: CAC87888, 36: BAA04065, 37: I38605, 38: AAG60018, 39: AAG60019, 40: BAB71805, 41: AAA83223, 42: AAF21468, 43: AAB70917, 44: AAG27061, 45: ZP_00067236, 46: CAB61662, 47: BAA03404, 48: BAA02168, 49: CAB94547, 50: AAG35112, 51: AAG35111, 52: AAO42981, 53: BAA13489, 54: BAA35140, 55: AAL78814, 56: EAA26709, 57: AAA96515, 58: EAA36073, 59: AAF19616, 60: BAB40591, 61: CAA45468, 62: CAB44709, 63: CAA72201, 64: NP_454628, 65: T44440, 66: AAF21123, 67: BAB79620, 68: AAF21120, 69: NP_232428, 70: BAA78114, 71: AAL37255, 72: AAO08114, 73: AAK96293, 74: AAF33549, 75: AAC59123, 76: AAA66756, 77: AAC63792, 78: AAA93130, 79: AAF21124, 80: AAB49933, 81: 224972, 82: AAK72610, 83: AAB97779. 


\section{K. Lohtander et al.}

A similar situation also applied to the chitinases of Nicotiana tabacum and Betula pendula. As coniferous (Picea and Pinus) chitinases were basal in both clades A and D, it seems that the divergence of class I and IV chitinases not only predates the divergence of monocots and dicots (as suggested by Hamel et al., 1997), but also predates the divergence of gymnosperms and angiosperms. However, more chitinase sequences from gymnosperms are needed to confirm this.

The phylogenetic tree (Fig. 1) supported the view that class II chitinases have arisen from class I chitinases (Hamel et al., 1997). Moreover, the result indicated that class II chitinases, as a group, are polyphyletic and have originated from both class I and class IV chitinases.

In addition to the chitinases of Burkholderia gladioli and Streptomyces species, a class IV-type chitinase is also found in Phytophthora infestans, a plant-pathogenic oomycete. According to our analysis, Phytophthora chitinase grouped together with the bacterial chitinases, these together forming a sister group to class IV chitinases from plants, indicating that all presently known non-plant class IV chitinases have a common evolutionary origin. If these chitinases were once transferred from an eukaryotic organism to bacteria, as suggested by Ohno et al. (1996), Watanabe et al. (1999) and Kong et al. (2001), this may have occurred only once, since the bacterial sequences formed a monophyletic group (Fig. 1). The absence of this type of chitinase from all other completely sequenced bacteria (including other species of Burkholderia; Kong et al., 2001) and other organisms supports the possibility of HGT. Both Phytophthora infestans and Burkholderia gladioli are plant pathogens, which may have facilitated gene transfer between the organisms. It is of additional interest that some strains of Burkholderia gladioli with type IV chitinases show an ability to protect plants from fungal pathogens (Kong et al., 2001). Among other organisms possessing proteins with some sequence similarity with family 19 glycosyl hydrolases are Encephalitozoon cuniculi, an organism causing encephalitozoonosis in humans and dogs (Snowden et al., 1999), bacteria Vibrio cholerae and Salmonella typhimuri and nematodes Caenorhabditis elegans and Ascaris suum. However, as the sequences were only ambiguously alignable with the chitinases included in this study, they were excluded from the final data set.

The phylogenetic tree of the class III chitinases (Fig. 2) supports the view of Hamel et al. (1997) according to whom the origin of class III chitinases predates the diversification of fungi and plants. However, according to our analyses, class III chitinases are also found in some bacteria belonging to different taxonomic groups, but they are not found in basidiomycetous fungi. While numerous class III chitinases are known from plants (Hamel et al., 1997), only one plant chitinase belonging to class V has been reported (Melchers et al., 1994). This class $\mathrm{V}$ chitinase sequence from tobacco (Nicotiana tabacum) was nested within animal chitinases in a phylogenetic tree (Sun et al., 1999). In this study, class V chitinase-like sequence was identified from a silver birch EST-library, and also class V chitinases from some other plants were found in GenBank. The plant class V chitinases formed a monophyletic group in the phylogenetic tree (Fig. 4), and instead of being nested within metazon chitinases (see Sun et al., 1999), they formed a sister group to a clade consisting of all the other eukaryote sequences and one cyanobacterial sequence, but this clade had no bootstrap support. In accordance with the study of Hawtin et al. (1997), the tree indicates at least one horizontal gene transfer event between viruses and bacteria, since a group consisting of viruses is nested within a bacterial clade with very good bootstrap support. Our result further supports the view of Cottrell et al. (2000), according to which several horizontal gene transfer events in this group of chitinases have presumably occurred, especially among bacteria.

\section{Implications for HGT from chitinase transgenic silver birch to other organisms}

HGT of plant DNA requires the existence of free DNA that should be of sufficient length and persist long enough for uptake. Furthermore, a bacterial recipient should be able to incorporate, maintain and use the incoming DNA (e.g. Conner et al., 2003; Nielsen et al., 2007), which depends on the homologous sequences in the recipient genome (de Vries et al., 2001, Monier et al., 2007). According to Dale et al. (2002), the impact of free DNA of transgenic origin is likely to be negligible compared with the large amount of total free DNA in the soil. Some studies also showed that the persistence of naked transgenic DNA in soil (Gebhard and Smalla, 1999) or in decomposing leaves (Hay et al., 2002) is presumably not long enough for the uptake of DNA by bacterial cells. According to the present view, natural transformation in soil typically occurs at rates below $10^{-7}$ transformants per recipient (Nielsen et al., 2000), and much lower frequencies between transgenic DNA and bacteria under natural conditions are expected (Nielsen and Townsend, 2004). Hence, the risks linked to HGT have generally not been considered as key concern in the cultivation of GM plants (see e.g. van Frankenhuyzen and Beardmore, 2004). However, as risk is a function of both the likelihood (frequency) and consequences of an event, there have been calls for more attention to the effects of HGT events (e.g. Heinemann and Traavik, 2004, Nielsen and Townsend, 2004).

The establishment of the horizontally-transferred transgene DNA in a new host will depend on the 
prevailing selection pressures. Most horizontally transferred transgenes are likely to cause negative effects on transformant's survival, and even transgenes that do not affect transformant's survival are likely to be lost over time (Nielsen and Townsend, 2004). Consequently, the main interest also in the case of chitinase transgenic silver birch should be focused on the consequences of HGT. The transferred sequence is originally from sugar beet, but the microbial communities associated with birch and found in forest soils are different and more diverse than those of agricultural soils, including e.g. diverse communities of ectomycorrhizal fungi, and the selection pressures are different. Furthermore, the evaluations of the effects of HGT of the transgene should not be separated from the evaluations of the effects of the other components of the plasmid used in the transformation, such as promoters and selection markers like the nptII gene.

From the risk assessment point of view, it is important to consider all the potential functions of the transgene. In general, chitinases are involved in many cellular functions. Some chitinase genes are able to encode antifreeze proteins or have a dual function encoding both pathogenesis-related proteins and antifreeze proteins (Hon et al., 1995), and high expression of a gene belonging to class IV chitinases has been detected in ripening grape fruits (Robinson et al., 1997). Chitinases may also have various other not so well-known roles during growth and development, e.g. during embryogenesis (Collinge et al., 1993). In addition, the chitin-binding domain of a chitinase belonging to family 19 glycosyl hydrolases is the major allergen of Persea americana (Sowka et al., 1998). However, according to our phylogenetic analysis, Persea americana chitinase groups together with the class I chitinases and is thus only distantly related with the chitinase of Beta vulgaris used for the transformation of silver birch.

The use of phylogenetic analyses in risk assessment aids in the observation of unintended HGT events of transgenes. For example, phylogenetic analysis of chitinases has revealed past HGT events, but the result also indicates that transferred chitinases must have resulted in favorable genetic changes that have survived over time due to positive selection.

However, the implications and interpretation of different phylogenetic outcomes in a biological risk assessment are yet to be established. The observation that certain genes frequently transfer between species on an evolutionary timescale can be interpreted in a different manner. For example, frequent historical transfer events of a certain gene may indicate that HGT has happened naturally, and therefore it does not cause additional risk when using transgenes. On the other hand, the same phenomenon also indicates that the gene has resulted in positive selection in the recipient organism and has the ability to become a permanent part of the recipient genome.

\section{CONCLUSIONS}

The increasing number of sequences in GenBank and the availability of databases, such as the 'The Horizontal Gene Transfer DataBase' (HGT-DB) of Garcia-Vallve et al. (2003), provide important resources that can be used in phylogenetic studies dealing with HGT. In the future, when data from numerous phylogenetic analyses can be combined, the frequencies and possible evolutionary significance of natural interkingdom HGT events can be more exactly estimated. Our present study supports the hypothesis that some class IV chitinases in bacteria have evolved from eukaryotic chitinases via horizontal gene transfer (Kong et al., 2001; Ohno et al., 1996; Watanabe et al., 1999). The available evidence suggests that the horizontal gene transfer event of a eukaryotic chitinase IV gene may have occurred only once. However, the effects of the possible HGT event, independent of frequency at which it might occur, are difficult to estimate because the effects are tightly linked with the prevailing selection pressures.

\section{MATERIALS AND METHODS}

\section{Alignment of sequences}

Mainly amino acid sequences were employed, because of the relative ease of the alignment of the sequences, even from distantly related organisms, as compared to DNA sequences. However, DNA sequences of closely related class IV chitinases were also analyzed. Silver birch chitinase DNA sequences were translated into amino acid sequences using the BioEdit program (Hall, 1999). After translation, several PSI Blastsearch procedures (Altschul et al., 1997) were performed in order to find all the chitinases belonging to glycosyl hydrolase families 18 and 19 from the GenBank.

Sequences were aligned using the ClustalW (Thompson et al., 1994) alignment program. All the resulting alignments were deposited in TreeBase (http://www. treebase.org/treebase/index.html). Sequences belonging to the two families (18 and 19) were analysed separately, as there was no sequence similarity between them. Furthermore, within the family 18 glycosyl hydrolases, sequences of the chitinases belonging to classes III and $\mathrm{V}$ were aligned separately. Although these sequences shared some conserved regions, they were still too different to be combined into one data set. 
A gap opening penalty of 10 and gap extension penalty of 0.05 were used for the alignment of the glycosyl hydrolase family 19 sequences. Single gaps were coded as character states in order to make use of all data in the data set. Long gaps ( $>2$ aa) were replaced by question marks and coded as binary characters (presence/absence) at the end of the data set. This prevented long gaps from gaining excessive weight in the phylogenetic analysis, but made sure that some phylogenetic information from gaps could be utilized. DNA sequences corresponding to the class IV chitinase amino acid sequences used in the protein analysis were aligned using parameters 10/5 (gap opening/gap extension penalty). In the alignment of glycosyl hydrolase family 18 sequences the gap opening and gap extension parameters were 5/0.05 for class III chitinase sequences, and 3/0.02 for class $\mathrm{V}$ chitinase sequences. The small values for the latter group were chosen because of considerable length variation in the sequences. Gaps were coded as missing data in both analyses, because neither data set had obvious indel patterns, similar to those observed among family 19 glycosyl hydrolases.

\section{Phylogenetic analyses}

Only the conserved catalytic domains of chitinases were used in the phylogenetic analyses. Phylogenetic trees were reconstructed using the heuristic search option in PAUP 4.0, with a random addition sequence (10 replicates) and tree bisection reconnection (TBR) branchswapping options (Swofford, 2000). Support for each node was estimated using bootstrapping (5000 reps.), as implemented in PAUP. Midpoint rooting was used in all amino acid analyses, due to uncertainty of suitable outgroups. Class I and II chitinases of Arabidopsis thaliana were chosen as outgroups for the analysis of the class IV chitinase DNA sequences.

All sequences obtained from the GenBank were first subjected to preliminary phylogenetic analyses (trees not shown). From a vast number of sequences in the initial phylogenetic trees, several representative examples of all groups were picked for further analyses. These included several examples from such plant families (e.g. Brassicaceae, Fabaceae, Poaceae, Solanaceae) that had chitinases in more than one group in the initial phylogenetic trees. Thus, all sequence groups within the preliminary trees were sampled for subsequent analyses (in which only some taxa were included from each group).

\section{ACKNOWLEDGEMENTS}

We thank Prof. Jaakko Kangasjärvi and Dr. Yrjö Helariutta for providing EST sequences and Dr. Juha
Immanen for searching the sequences. We also thank the editors and the reviewers for their useful comments. This study was financially supported by the Academy of Finland (Project 176 710).

Received March 28, 2008; accepted July 7, 2008.

\section{REFERENCES}

Altschul SF, Madden TL, Schäffer AA, Zhang J, Zhang Z, Miller W, Lipman DJ (1997) Gapped BLAST and PSI-BLAST: a new generation of protein database search programs. Nucleic Acids Res. 24: 3389-3402

Arlorio M, Ludwig A, Boller T, Bonfante P (1992) Inhibition of fungal growth by plant chitinases and $\beta$-1,3-glucanases. Protoplasma 171: 34-43

Asao H, Nishizawa Y, Arai S, Sato T, Hirai M, Yoshida K, Shinmyo A, Hibi T (1997) Enhanced resistance against a fungal pathogen Sphaerotheca humuli in transgenic strawberry expressing a rice chitinase gene. Plant Biotechnol. 14: 145-149

Baker ME (1998) Evolution of mammalian 11 beta- and 17 beta-hydroxysteroid dehydrogenases-type 2 and retinol dehydrogenases from ancestors in Caenorhabditis elegans and evidence for horizontal transfer of a eukaryote dehydrogenase to E. coli. J. Ster. Biochem. Mol. Biol. 66: 355-363

Bartnicki-Garcia S (1968) Cell wall chemistry, morphogenesis, and taxonomy of fungi. Ann. Rev. Microbiol. 22: 87-108

Bertolla F, Simonet P (1999) Horizontal gene transfers in the environment, natural transformation as a putative process for gene transfers between transgenic plants and microorganisms. Res. Microbiol. 150: 375-384

Beintema J (1994) Structural features of plant chitinases and chitin-binding proteins. FEBS Letters 350: 159-163

Bolar JP, Norelli JL, Wong K-W, Hayes CK, Harman GE, Aldwinckle HS (2000) Expression of endochitinase from Trichoderma harzianum in transgenic apple increases resistance to apple scab and reduces vigor. Phytopathology 90: $72-77$

Bolar J, Norelli J, Harman G, Brown S, Aldwinckle H (2001) Synergistic activity of endochitinase and exochitinase from Trichoderma atroviride (T. harzianum) against the pathogenic fungus (Venturia inaequalis) in transgenic apple plants. Transgenic Res. 10: 533-543

Boller T (1987) Hydrolytic enzymes in plant disease resistance. In Kosuge T, Nester EW, eds, Plant-Microbe Interactions, Macmillan, New York, Vol. 2, pp 385-413

Brinkman FSL, MacFarlane ELA, Warrener P, Hancoc $\mathbf{R}$ (2001) Evolutionary relationships among virulenceassociated histidine kinases. Infect. Immun. 69: 5207-5211

Brinkman FSL, Blanchard JL, Cherkasov A, Av-Gay Y, Brunham RC, Fernandez RC, Finlay B, Otto SP, Ouellette 
BFF, Keeling PJ, Rose AM, Hancock REW, Jones SJM (2002) Evidence that plant-like genes in Chlamydia species reflect an ancestral relationship between Chlamydiaceae, cyanobacteria, and the choloroplast. Genome Res. 12: 11159-1167

Broglie K, Chet I, Holliday M, Cressman R, Biddle P, Knowlton S, Mauvais CJ, Broglie R (1991) Transgenic plants with enhanced resistance to the fungal pathogen Rhizoctonia solani. Science 254: 1194-1197

Buades C, Moya A (1996) Phylogenetic analysis of the isopenicillin-N-synthetase horizontal gene transfer. J. Mol. Evol. 42: 537-542

Collinge DB, Kragh KM, Mikkelsen JD, Nielsen KK, Rasmussen U, Vad K (1993) Plant chitinases. Plant J. 3: $31-40$

Conner AJ, Glare TR, Nap J-P (2003) The release of genetically modified crops into the environment. Part II. Overview of ecological risk assessment. Plant J. 33: 19-46

Cottrell MT, Wood DN, Yu L, Kirchman DL (2000) Selected chitinase genes in cultured and uncultured marine bacteria in the $\alpha$ - and $\beta$ - subclasses of the Proteobacteria. Appl. Environ. Microbiol. 66: 1195-1201

Dale PJ, Clarke B, Fontes EMG (2002) Potential for the environmental impact of transgenic crops. Nature Biotechnol. 20: $567-574$

Datta K, Koukolíková-Nicola Z, Baisakh N, Oliva N, Datta SK (2000) Agrobacterium-mediated engineering for sheath blight resistance of indica rice cultivars from different ecosystems. Theor. Appl. Genet. 100: 832-839

Davies G, Henrissat B (1995) Structures and mechanisms of glycosyl hydrolases. Structure 3: 853-859

Davis JM, Clarke HR, Bradshaw HD Jr, Gordon MP (1991) Populus chitinase genes, structure, organization, and similarity of translated sequences to herbaceous plant chitinases. Plant Mol. Biol. 17: 631-639

De Vries J, Meier P, Wackernagel W (2001) The natural transformation of the soil bacteria Pseudomonas stutzeri and Acinetobacter sp. by transgenic plant DNA strictly depends on homologous sequences in the recipient cells. FEMS Microbiology Letters 195: 211-215

Emani C, Garcia JM, Lopata-Finch E, Pozo MJ, Uribe P, Kim D-J, Sunikumar G, Cook DR, Kenerley CM, Rathore KS (2003) Enhanced fungal resistance in transgenic cotton expressing an endochitinase gene from Trichoderma virens. Plant Biotech. J. 1: 321-336

Furner IJ, Huffman GA, Amasino RM, Garfinkel DJ, Gordon MP, Nester EW (1986) An Agrobacterium transformation in the evolution of the genus Nicotiana. Nature 319: 422-427

Gamieldien J, Ptitsyn A, Hide W (2002) Eukaryotic genes in Mycobacterium tuberculosis could have a role in pathogenesis and immunomodulation. Trends Genet. 18: 5-8
Garcia-Vallve S, Guzman E, Montero MA, Romeu A (2003) HGT-DB, a database of putative horizontally transferred genes in prokaryotic complete genomes. Nucleic Acids Res. 31: $187-189$

Gay P (2001) The biosafety of antibiotic resistance markers in plant transformation and the dissemination of genes through horizontal gene flow. In Custers R, ed, Safety of genetically engineered crops, Zwijnaarde, Belgium, Flanders Interuniversity Institute for Biotechnology, pp 135-159

Gebhard F, Smalla K (1999) Monitoring field releases of genetically modified sugar beets for persistence of transgenic plant DNA and horizontal gene transfer. FEMS Microbiol. Ecol. 28: 261-272

Grison R, Grezes-Besset B, Schneider M, Lucante N, Olsen L, Leguay JJ, Toppan A (1996) Field tolerance to fungal pathogens of Brassica napus constitutively expressing a chimeric chitinase gene. Nature Biotechnol. 14: 643-646

Hall TA (1999) BioEdit: a user-friendly biological sequence alignment editor and analysis program for Windows 95/98/NT. Nucleic Acids Symp. Ser. 41: 95-98

Hamel F, Boivin R, Tremblay C, Bellemare G (1997) Structural and evolutionary relationships among chitinases of flowering plants. J. Mol. Evol. 44: 614-624

Hawtin RE, Zarkowska T, Arnold K, Thomas CJ, Gooday GW, King LA, Kuzio JA, Possee RD (1997) Liquefaction of Autographa californica nucleopolyhedrovirus-infected insects is dependent on the integrity of virus-encoded chitinase and cathepsin genes. Virology 238: 243-253

Hay I, Morency M-J, Séguin A (2002) Assessing the persistence of DNA in decomposing leaves of genetically modified poplar leaves. Can. J. For. Res. 32: 977-982

Heinemann JA, Traavik T (2004) Problems in monitoring horizontal gene transfer in field trials of transgenic plants. Nature Biotechnol. 22: 1105-1109

Heuer H, Smalla K (2007) Horizontal gene transfer between bacteria. Environ. Biosafety Res. 6: 3-13

Hoffman T, Golz C, Schieder O (1994) Foreign DNA sequences are received by a wild-type strain of Aspergillus niger after co-culture with transgenic higher plants. Curr. Genet. 27: $70-76$

Holmgren A, Bränden C (1989) Crystal structure of chaperone protein PapD reveals an immunoglobulin fold. Nature 342: $248-251$

Hon WC, Griffith M, Mlynarz A, Kwok YC, Yang DSC (1995) Antifreeze proteins in winter rye are similar to pathogenesis-related proteins. Plant Physiol. 109: 879-889

Intrieri M, Buiatti M (2001) The horizontal transfer of Agrobacterium rhizogenes genes and the evolution of the genus Nicotiana. Mol. Phylogenet. Evol. 20: 100-110

Katz LA (1996) Transkingdom transfer of the phosphoglucose isomerase gene. J. Mol. Evol. 43: 453-459 
Ke D, Boissinot M, Huletsky A, Picard FJ, Frenette J, Ouellette M, Roy PH, Bergeron MG (2000) Evidence for horizontal gene transfer in evolution of elongation factor $\mathrm{Tu}$ in enterococci. J. Bacteriol. 182: 6913-6920

Klotz MG, Klassen GR, Loewen PC (1997) Phylogenetic relationships among prokaryotic and eukaryotic catalases. Mol. Biol. Evol. 14: 951-958

Kong H, Shimosaka M, Ando Y, Nishiyama K, Fujii T, Miyashita K (2001) Species-specific distribution of a modular family 19 chitinase gene in Burkholderia gladioli. FEMS Microbiol. Ecol. 37: 135-141

Koonin EV, Makarova KS, Aravind L (2001) Horizontal gene transfer in prokaryotes, quantification and classification. Ann. Rev. Microbiol. 55: 709-742

Koski LB, Morton RA, Golding GB (2000) Codon bias and base composition are poor indicators of horizontally transferred genes. Mol. Biol. Evol. 18: 404-412

Lilley AK, Fry JC, Day MJ, Bailey MJ (1994) In situ transfer of an exogenously isolated plasmid between Pseudomonas spp. in sugar beet rhizosphere. Microbiology 140: 27-33

Lorito M, Woo SL, Fernandez IG, Colucci G, Harman GE, Pintor-Toro JA, Filippone E, Muccifora S, Lowrence CB, Zoina A, Tuzun S, Scala F (1998) Genes from mycoparasitic fungi as a source for improving plant resistance to fungal pathogens. Proc. Natl. Acad. Sci. USA 95: 7860-7865

Mauch F, Mauch-Mani B, Boller T (1988) Antifungal hydrolases in pea tissue. II. Inhibition of fungal growth by combinations of chitinase and $\beta$-1,3-glucanase. Plant Physiol. 88: 936-942

Melchers LS, Apotheker-de Groot M, van der Knaap JA, Ponstein AS, Sela-Buurlage MB, Bol JF, Cornelissen BJ, van den Elzen PJM, Linthorst HJM (1994) A new class of tobacco chitinases homologous to bacterial exo-chitinases displays antifungal activity. Plant J. 5: 469-480

Monier JM, Bernillon D, Kay E, Faugier A, Rybalka O, Dessaux Y, Simonet P, Vogel TM (2007) Detection of potential transgenic plant DNA recipients among bacteria. Environ. Biosafety Res. 6: 71-83

Nielsen KM, Townsend JP (2004) Monitoring and modeling horizontal gene transfer. Nature Biotechnol. 22: 1110-1114

Nielsen KM, Gebhard F, Smalla K, Bones AM, van Elsas JD (1997) Evaluation of possible horizontal gene transfer from transgenic plants to the soil bacterium Acinetobacter calcoaceticus BD413. Theor. Appl. Genet. 95: 815-821

Nielsen KM, Bones AM, Smalla K, van Elsas JD (1998) Horizontal gene transfer from transgenic plants to terrestrial bacteria - rare event. FEMS Microbiol. Res. 22: 79-103

Nielsen KM, van Elsas JD, Smalla K (2000) Transformation of Acinetobacter sp. Strain BD413 (pFGnptII) with transgenic plant DNA in soil microcosms and effects of kanamycin on selection of transformants. Appl. Environ. Microbiol. 66: $1237-1242$
Nielsen KM, Johnsen PJ, Bensasson D, Daffonchio D (2007) Release and persistence of extracellular DNA in the environment. Environ. Biosafety Res. 6: 37-53

Ochman H, Lawrence JG, Groisman EA (2000) Lateral gene transfer and the nature of bacterial innovation. Nature $\mathbf{4 0 5}$ : 299-304

Ohno T, Armand S, Hata T, Nikaidou N, Henrissat B, Mitsutomi M, Watanabe T (1996) A modular family 19 chitinase found in the prokaryotic organism Streptomyces griseus HUT 6037. J. Bacteriol. 17: 5065-5070

Pappinen A, Degefu Y, Syrjälä L, Keinonen K, von Weissenberg K (2002) Transgenic silver birch (Betula pendula) expressing a sugar beet chitinase 4 gene shows enhanced resistance to Pyrenopeziza betulicola. Plant Cell Rep. 20: 1046-1051

Pasonen H-L, Seppänen S-K, Degefu Y, Rytkönen A, von Weissenberg K, Pappinen A (2004) Field performance of chitinase transgenic silver birches (Betula pendula): resistance to fungal diseases. Theor. Appl. Genet. 109: 562-570

Pontiroli A, Simonet P, Frostegard A, Vogel TM, Monier J-M (2007) Fate of transgenic plant DNA in the environment. Environ. Biosafety Res. 6: 15-35

Robinson SP, Jacobs AK, Dry IB (1997) A class IV chitinase is highly expressed in grape berries during ripening. Plant Physiol. 114: 771-778

Royo J, Gimez E, Hueros G (2000) CMP-KDO synthetase, a plant gene borrowed from gram negative eubacteria. Trends Genet. 16: 432-433

Schlumbaum A, Mauch F, Vögeli U, Boller T (1986) Plant chitinases are potent inhibitors of fungal growth. Nature $\mathbf{3 2 4}$ : 365-367

Snowden K, Logan K, Didier ES (1999) Encephalitozoon cuniculi strain III is a cause of encephalitozoonosis in both humans and dogs. J. Infect Dis. 180: 2086-2088

Sowka S, Hsieh LS, Krebitz M, Akasawa A, Martin BM, Starrett D, Peterbauer CK, Scheiner O, Breiteneder H (1998) Identification and cloning of Prs a 1, a 32-kDa endochitinase and major allergen of avocado, and its expression in the yeast Pichia pastoris. J. Biol. Chem. 273: 28091-28097

Sun L, Adams B, Gurnon JR, Ye Y, Van Etten J (1999) Characterization of two chitinase genes and one chitisanase gene encoded by Chlorella virus PBCV-1. Virology 263: 376-387

Swofford DL (2000) PAUP*. Phylogenetic Analysis Using Parsimony (*and Other Methods). Version 4. Sinauer Associates, Sunderland, Massachusetts

Thompson JD, Higgins DG, Gibson TJ (1994) CLUSTAL W, improving the sensitivity of progressive multiple sequence alignment through sequence weighting, positions-specific gap-penalties and weigh matrix choise. Nucleic Acids Res. 22: 4673-4680

Troxler J, Azelvandre P, Zala M, Defago G, Haas D (1997) Conjugative transfer of chromosomal genes between 
fluorescent pseudomonas in the rhizosphere of wheat. Appl. Environ. Microbiol. 63: 213-219

van Elsas JD, Nikkel M, van Overbeek LS (1989) Detection of plasmid RP4 transfer in soil and rhizosphere, and the occurrence of homology to RP4 in soil bacteria. Curr. Microbiol. 19: $375-381$

van Elsas JD, Turner S, Bailey MJ (2003) Horizontal gene transfer in the phytosphere. New Phytol. 157: 525-537

van Frankenhuyzen K, Beardmore T (2004) Current status and environmental impact of transgenic forest trees. Can. J. For. Res. 34: 1163-1180

Vellice GR, Diaz Ricci JC, Hernández L, Castagnaro AP (2006) Enhanced resistance to Botrytis cinerea mediated by the transgenic expression of the chitinase gene $\operatorname{ch} 5 B$ in strawberry. Transgenic Res. 15: 57-68
Vierheilig H, Alt-Hug M, Wiemken A, Boller T (2001) Hyphal in vitro growth of the arbuscular mycorrhizal fungus Glomus mossae is affected by chitinase but not by $\beta-1,3-$ glucanase. Mycorrhiza 11: 279-282

Watanabe T, Kanai R, Kawase T, Tanabe T, Mitsutomi M, Sakuda S, Miyashita K (1999) Family 19 chitinases of Streptomyces species, characterization and distribution. Microbiology 145: 3353-3363

Wiener P, Egan S, Huddleston A, Wellington E (1998) Evidence for transfer of antibiotic-resistance genes in soil populations of Streptomycetes. Mol. Ecol. 7: 1205-1216

Wolfenbarger LL, Pfifer PR (2000) The ecological risks and benefits of genetically engineered plants. Science 290: 2088-2093 